\title{
Relationship between mozzarella yield and milk composition, processing factors, and recovery of whey constituents
}

\author{
D. C. Sales, ${ }^{*}$ A. H. N. Rangel, ${ }^{*}$ S. A. Urbano, ${ }^{* 1}$ Alfredo R. Freitas, † Humberto Tonhati,ł L. P. Novaes, ${ }^{*}$ \\ M. I. B. Pereira, ${ }^{*}$ and L. H. F. Borba* \\ *Universidade Federal do Rio Grande do Norte, Natal, Brazil 59078970 \\ †Empresa Brasileira de Pesquisa Agropecuária (Aposentado), São Paulo, Brazil 13560970 \\ ‡Faculdade de Ciências Agrárias e Veterinárias, Universidade Estadual Paulista Júlio de Mesquita Filho, São Paulo, Brazil 14884900
}

\begin{abstract}
Our aim was to identify the relationship between mozzarella cheese yield and buffalo milk composition, processing factors, and recovery of whey constituents. A production of 30 batches of mozzarella cheese at a dairy industry in northeast Brazil (Rio Grande do Norte) was monitored between March and November 2015. Mozzarella yield and 32 other variables were observed for each batch, and divided into 3 groups: milk composition variables (12); variables involved in the cheesemaking process (14); and variables for recovery of whey constituents (6). Data were analyzed using descriptive statistics, Pearson correlation, and principal component analysis. Most of the correlations between milk composition variables and between the variables of the manufacturing processes were not significant. Significant correlations were mostly observed between variables for recovery of whey constituents. Yield only showed significant correlation with time elapsed between curd cuttings and age of the starter culture, and it showed greater association with age of the starter culture, time elapsed between curd cuttings, and during stretching, as well as with milk $\mathrm{pH}$ and density. Thus, processing factors and milk characteristics are closely related to dairy efficiency in mozzarella manufacturing. Key words: Bubalus bubalis, dairy product, efficiency, industry, cheese
\end{abstract}

\section{INTRODUCTION}

Mozzarella cheese is a typical product from Italy; however, its manufacture is relatively recent in Brazil, where a similar process to the Italian method is used, necessarily using whole buffalo milk (Brazilian Association of Buffalo Breeders, 2014). Mozzarella cheese has an already established niche market with a promising

Received December 2, 2016.

Accepted January 30, 2017.

${ }^{1}$ Corresponding author: stela_antas@yahoo.com.br future in Brazil due to the possibility of adding greater value compared with cheese made with cow milk. Thus, the number of industries that use buffalo milk in the manufacturing of their products is growing, with mozzarella cheese being foremost among these products (Brazilian Association of Buffalo Breeders, 2014; Tonhati et al., 2011).

In the manufacturing of dairy products, yield can indicate productive success in practical terms and is a valuable tool for improving the process and cost-benefit balance of the company. Solids concentration in buffalo milk, being mostly fat, protein or casein, and minerals, enables efficient production and quality of various derivatives to be higher than bovine milk (Rangel et al., 2011; Tonhati et al., 2011; Cipolat-Gotet et al., 2015). Italian industry is able achieve about 20 to $22 \mathrm{~kg}$ of mozzarella from processing $100 \mathrm{~L}$ of buffalo milk, a yield almost 50\% higher than bovine milk (Citro, 2010).

Several factors have an effect on the yield of dairy products, mainly those related to the technological quality of milk. These are directly related to the animals (i.e., genetics, nutrition, physiological, and health status) or the handling of raw materials (i.e., hygiene conditions, techniques used, and so on; Abd El-Gawad and Ahmed, 2011; Cipolat-Gotet et al., 2015; Sales et al., 2016). Especially for stretched-curd cheeses, yield mainly varies depending on the processing technology (stretching time), the raw material (industrial or natural yeast), and on the characteristics of the finished products (Citro, 2010).

The expression of cheese yield is important in 2 main applications: for economic manufacturing control and to express experimental results of the industry (Furtado, 2005; Abd El-Gawad and Ahmed, 2011). Therefore, this enables comparing the effective use of milk in various production processes, livestock, and animal species. Cheesemaking efficiency can be obtained by calculating the actual yield (Furtado, 2005) or its prediction before production, often being used for the payment of milk quality, and also for production estimates (Abd El-Gawad and Ahmed, 2011; Sales et al., 2016). 


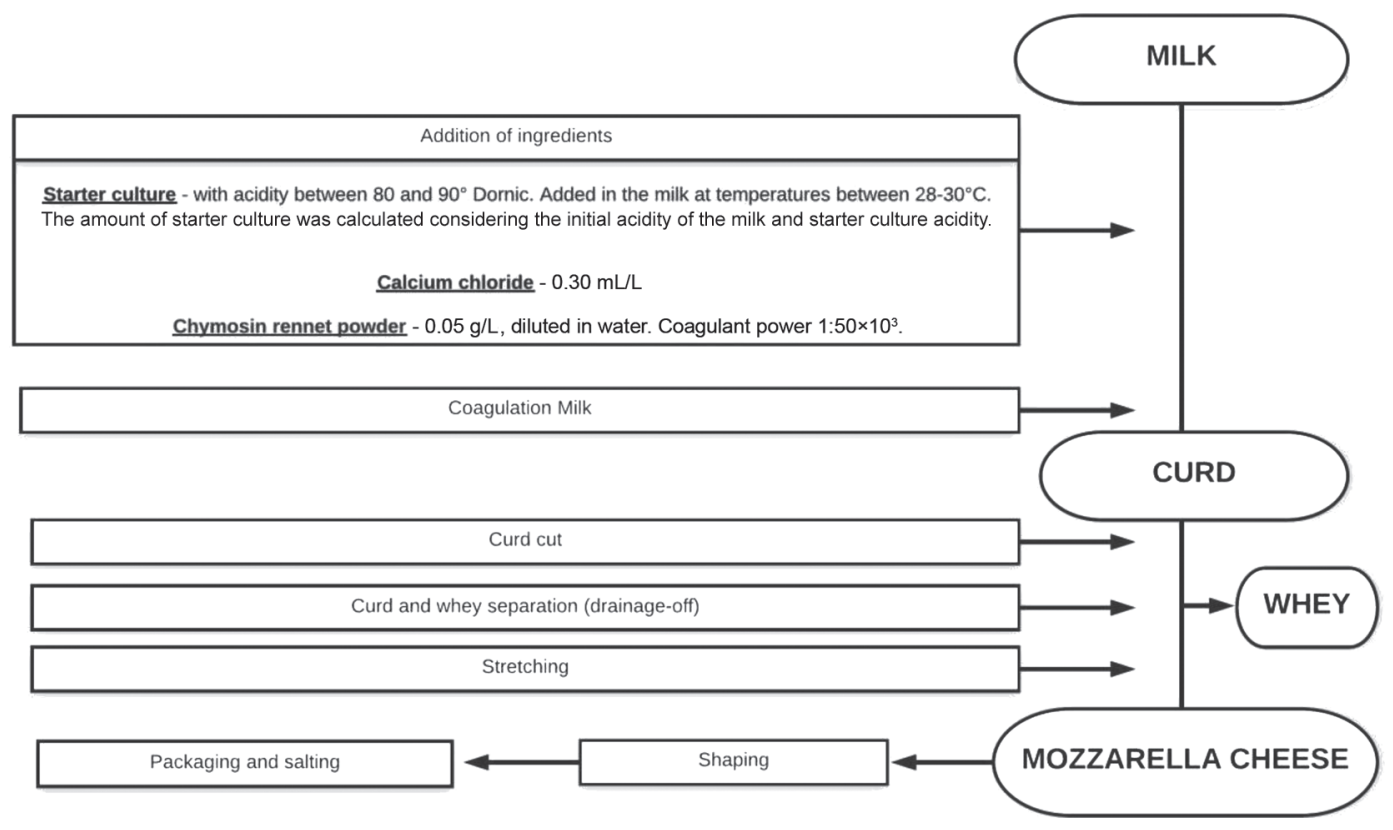

Figure 1. Steps of mozzarella cheese manufacturing technology.

Knowledge regarding the relationship between mozzarella cheese yield and productive aspects can provide complementary calculation methods of manufacturing efficiency to the already existing methods and also allow greater understanding about the milk technology and its use, specifically based on information regarding mozzarella cheese. In this sense, the present study aimed to identify the relationship between mozzarella cheese yield and variables of milk composition, processing and the recovery of whey constituents.

\section{MATERIALS AND METHODS}

\section{Data Collection}

The study was conducted in a dairy plant located in Taipu, Rio Grande do Norte, Brazil. The industry has certifications from the Federal Inspection Service and from the Brazilian Association of Buffalo Breeders (100\% buffalo purity label), and also has a trademark for mozzarella cheese and other products made from buffalo milk. Processing of 30 lots of mozzarella cheese was monitored weekly from April to November 2015, respecting the industry schedule. The average number of days between monitoring the production lots was $7.45 \pm 2.69 \mathrm{~d}$. The milk used for manufacturing the cheese was produced by the herd from the dairy plant, containing an average of 350 lactating buffaloes. The animals were grazed in pasture under Voisin-type rotational stocking, with the predominant pastures being Brachiaria brizantha and Panicum maximum L. Massai.
Buffaloes were mechanically milked twice a day (morning and afternoon), without the presence of calves, with the adoption of all the procedures of good milking practices, such as the use of pre- and postdipping. The milking equipment was a double-20, single line type, with a low line in closed circuit.

\section{Mozzarella Cheese Manufacture}

Mozzarella was produced by enzymatic coagulation of milk following the recommendations from Citro (2010), to obtain a cheese very close in characteristics to the same Italian cheese. The manufacturing technology used for mozzarella cheese production consisted of the steps shown in Figure 1.

\section{Sample Collection}

A sample of raw milk was collected from the milk arrival flow at the receiving tank for each of the 30 lots monitored within the dairy plant, and a whey sample from mozzarella cheese at the end of drainage off the curd was collected directly from the production tank. They were identified, placed in plastic vials of $40 \mathrm{~mL}$, and maintained at a temperature between 4 and $7^{\circ} \mathrm{C}$ until analysis.

\section{Laboratory Analyses}

The milk samples were tested for physical-chemical analysis of $\mathrm{pH}$, acidity $\left[{ }^{\circ}\right.$ Dornic $(\mathbf{D})$ ], density $(\mathrm{g} / \mathrm{mL}$ at 
$15^{\circ} \mathrm{C}$ ), fat, protein, casein, lactose, TS, milk SNF (\%), and SCC $\left(\times 10^{3}\right.$ cells $\left./ \mathrm{mL}\right)$. However, the samples from cheese whey were also subjected to chemical analysis of fat, total protein, casein, lactose, TS, and SNF.

For determining protein, fat, lactose, and TS, the samples were subjected to duplicate analysis by infrared absorption (Bentley Instruments Inc., Chaska, MN). Acidity was determined by titration by $\mathrm{NaOH}$ with phenolphthalein indicator. We determined SCC using the Somaticell (Idexx Laboratories Inc., Westbrook, MA), following the manufacturer's protocol. Both analyzes were carried out at the Milk Quality Laboratory of the Federal University of Rio Grande do Norte (Laboleite, Macaiba, Rio Grande do Norte, Brazil).

Physical analysis of milk and starter culture $(\mathrm{pH}$ and acidity) were performed in the dairy plant laboratory itself. The $\mathrm{pH}$ was obtained through a digital portable meter, properly calibrated with 4.0 and 7.0 buffer solutions. The density of the milk was obtained using a thermal lactodensimeter gauge at $15^{\circ} \mathrm{C}$. The results from the physical tests of the starter culture (natural whey culture, from previous processing, collected at the end of the previous day's mozzarella manufacturing and stored in the freezer) were used to calculate the starter culture volume to be added to the milk during the process.

\section{Description of Variables}

The study considered a total of 32 variables, divided into 3 groups. Group 1 included milk composition variables fat content (FC, \%); total protein content (TOTPRO, \%); casein content (CAS, \%); caseinto-total protein ratio (CASTPR); lactose content (LAC, \%); TS content (\%); SNF content (\%); density at $15^{\circ} \mathrm{C}$ (DENS, g/mL); cryoscopic index [CrI; ${ }^{\circ}$ Horvet $\left.(\mathbf{H})\right]$; $\mathrm{pH}$; titratable acidity $\left(\mathbf{T A},{ }^{\circ} \mathrm{D}\right)$; and SCS $\left[\log _{2}(\mathrm{SCC} / 100,000)+3\right.$, in log cells $\left./ \mathrm{mL}\right]$. Group 2 included variables involved in the manufacturing process of mozzarella cheese, such as volume of milk used (L); pH of starter culture (PHSC); starter culture acidity (SCAC, ${ }^{\circ} \mathrm{D}$ ); age of the starter culture, time between the collection of the starter culture and its use (ASC, h); volume of starter culture used (VSC, L); volume of calcium chloride (VCACL, $\mathrm{mL} / \mathrm{L})$; volume of rennet (VRE, g); temperature of rennet addition (TEMPRE, ${ }^{\circ} \mathrm{C}$ ); average $\mathrm{pH}$ of curd during stretching (PHCU); coagulation time (COT, min); time between cuts (TCUTS, min); fermentation time (FERM1T, min); stretching time for the whole curd (STRT, min); and complete fermentation time (FERM2T, min). Group 3 represented recovery variables of whey constituents, including fat recovery from whey (FATREC,
\%); protein recovery from whey (PROTREC, \%); casein recovery from whey (CASREC, \%); lactose recovery from whey (LACREC, \%); TS recovery from whey (TSREC, \%); and SNF recovery from whey (SNFREC, \%).

Mozzarella yield (MY) considered in this study was interpreted using the MY variable in kilograms per kilogram (amount of milk employed per kilogram of produced cheese). The duration of steps was obtained by the difference (in hours or minutes) between the final time and initial time of the step.

\section{Mathematical Calculations}

The values obtained for SCC were transformed into SCS using the following procedure by Shook (1982): $\mathrm{SCS}=\log _{2}(\mathrm{SCC} / 100,000)+3$. The exact volume of milk used (VI) in the process and of residual whey for production (Vs) was calculated in liters $\left(\mathrm{cm}^{3}\right)$, considering the occupied area in the tank as follows: Vl (or $\mathrm{Vs})=\mathrm{H} \times \mathrm{W} \times \mathrm{L}$, where $\mathrm{H}=$ height reached by the milk blade in relation to the tank wall $(\mathrm{cm}) ; \mathrm{W}=$ width of the production tank $(\mathrm{cm})$; and $\mathrm{L}=$ length of the production tank $(\mathrm{cm})$.

The amount of starter culture (VSC) added to the process, in liters, was calculated taking into consideration the initial acidity of the milk and starter culture acidity, calculated as VSC $=(\mathrm{Vl} \times \mathrm{UA}) / \mathrm{ASC}$, where $\mathrm{VSC}=$ volume of starter culture required to raise the acidity of milk to "n" UA (L); Vl = volume of milk used (L); UA = units of acidity $\left({ }^{\circ} \mathrm{D}\right)$ of the milk, which should be increased with the addition of starter culture; and ASC $=$ acidity of starter culture $\left({ }^{\circ} \mathrm{D}\right)$.

The Vl (L) was converted into kilograms for use in the mozzarella yield equation: $\mathrm{Vlkg}=\mathrm{Vl} \times \mathrm{DENS}$, where Vlkg = volume of milk used $(\mathrm{kg}) ; \mathrm{Vl}=$ volume of milk used (L); DENS = density $(\mathrm{kg} / \mathrm{L})$.

Mozzarella yield (in $\mathrm{kg} / \mathrm{kg}$ ) was obtained by an equation adapted from Rossi et al. (1998), which represents the milk volume used to obtain $1 \mathrm{~kg}$ of cheese: $\mathrm{MY}=\mathrm{Vlkg} / \mathrm{VC}$, where $\mathrm{Vlkg}=$ volume of milk used in kilograms and $\mathrm{VC}=$ volume of produced cheese in kilograms.

The recovery of fat, protein, casein, lactose, TS, and SNF in the whey was obtained as proposed by Furtado and Pombo (1979): (c)REC $=\%$ Whey $/ \%$ Milk, where (c) = fat, total protein, casein, lactose, TS, or SNF; (c) REC $=$ recovery of whey constituents (\%); \% Whey $=$ content of the component (c) in whey (\%); and $\%$ Milk $=$ content of the component (c) in milk (\%).

\section{Statistical Analysis}

Data were initially submitted to exploratory analysis (amplitude, central trend measurements, skewness, 
kurtosis, SD, and CV). Data management techniques can detect interesting patterns and characteristics in the data that indicate possible models, patterns, or trends without involving large amounts of hypothesizing or theorizing on the subject.

An analysis of the Pearson correlation coefficient at $5 \%$ probability was carried out in this study to identify the linear relationship (association) between variables of each group and between them, and the yield. Studying the relationship between MY and milk composition factors, processing, and recovery of whey constituents involved several correlated characteristics. Principal component analysis is an exploratory multivariate technique and was used to understand the phenomenon of association between the correlated characteristics in a simplified and concise manner. Statistical analyzes were performed using the PROC CORR and PROC PRINCOMP procedures (ver. 9.1.3, SAS Institute Inc., Cary, NC).

According to Cochran and Cox (1978), non-normality of the data affects the obtained inferences, the estimation of fixed effects, the use of $\mathrm{T}$ and $\mathrm{F}$ tests, and the heterogeneity of error variance, and the non-normality of the data are more problematic in multivariate analysis than in univariate analyzes. However, the sample size of our study was considered large, considering that all the variables are continuous, and that the sample is greater or equal to 30. According to Gill (1978), as the sample size increases, the distributions start to present similar shape to the normal (distribution). Therefore, the application of statistical methods in our study are adequate, despite including variables with different distribution than the normal.

\section{RESULTS AND DISCUSSION}

The analysis was conducted in groups that bring together the variables according to their most important feature: whether it is a milk constituent, manufacturing process factor, or factors for recovery of whey constituents. The results of the current study are discussed separately for each group of variables $(1,2$, and 3$)$ to evidence their behavior, considering the data distribution and the association between them. Next, we effectively explain the relationship between the 3 groups of variables and MY.

Principal component analysis was carried out for each set of variables (milk composition, processing factors, recovery of whey constituents) and simultaneously for all variables to identify the association between them and MY. The values associated with the first (PC1), second (PC2), and third (PC3) principal components were obtained from the correlation matrix of each variable group and are arranged in Figures 2 to 5 .

\section{Group 1: Milk Composition}

Descriptive Analysis. Descriptive statistics for milk composition variables are presented in Table 1. Information on similarity between central trend measurements, comparison of zero skewness and kurtosis coefficients, dispersion of the data from the mean (CV and $\mathrm{SD}$ ), and amplitude of the data are considered jointly; the relationship of the closest variables from normal to the most distant was CASTPR, CAS, TOTPRO, TS, SNF, DENS, FC, TA, LAC, SCS, CrI, and pH.

Skewness coefficients were negative for FC, LAC, TS, $\mathrm{SNF}, \mathrm{CrI}, \mathrm{pH}$, and SCS, whereas the remaining variables, TOTPRO, CAS, CASTPR, DENS, and TA, showed positive skewness coefficient. Kurtosis coefficients were negative for FC, TOTPRO, CAS, TS, SNF, TA, and SCS, having a flatter (thinner-tailed) distribution than normal (platykurtic). In fact, the first 6 variables closer to normality represent data that suffer fewer effects of factors such as physiological, health, nutrition factors, and the handling of animals, for example; thus, they are less likely to change and have better homogeneity of its values when compared with other characteristics evaluated in milk. In general, the coefficient of variation was low for all physicochemical properties of milk, which is advantageous as it contributes to obtaining a product with standardized characteristics.

Pearson Correlation Analysis. Total solids correspond to all chemical constituents of milk, without water, and include FC, TOTPRO, and specific protein portions, such as CAS and LAC; thus, high positive and significant $(P<0.05)$ correlations between TS and other constituents were found (Table 2), similar to what happens in the relationship between such constituents and SNF $(P<0.05)$.

The correlation coefficients between CAS, TOTPRO, and CASTPR were high and significant $(P<$ $0.05)$. Casein is a proteic component that corresponds to about $80 \%$ of the total protein (Table 1), and its variation, therefore, has a close relationship with the variations in TOTPRO and CASTPR. Thus, the study of the relationship between CAS and cheese yield by multivariate analysis should also include other protein elements (TOTPRO, CASTPR), considering that they are all essential for the formation of cheese curd and yield (Abd El-Gawad and Ahmed, 2011).

According to Negri (2005), milk pH is influenced by various factors such as protein content and the presence of mastitis (high SCC and SCS) due to salt imbalance. Despite a strong relationship between protein constituents and SCS with $\mathrm{pH}$ not being found, we noted a high and significant correlation with DENS $(P<0.05)$. This can be explained by the fact that elements with a proteinaceous character (TOTPRO, CAS, and CASTPR) 


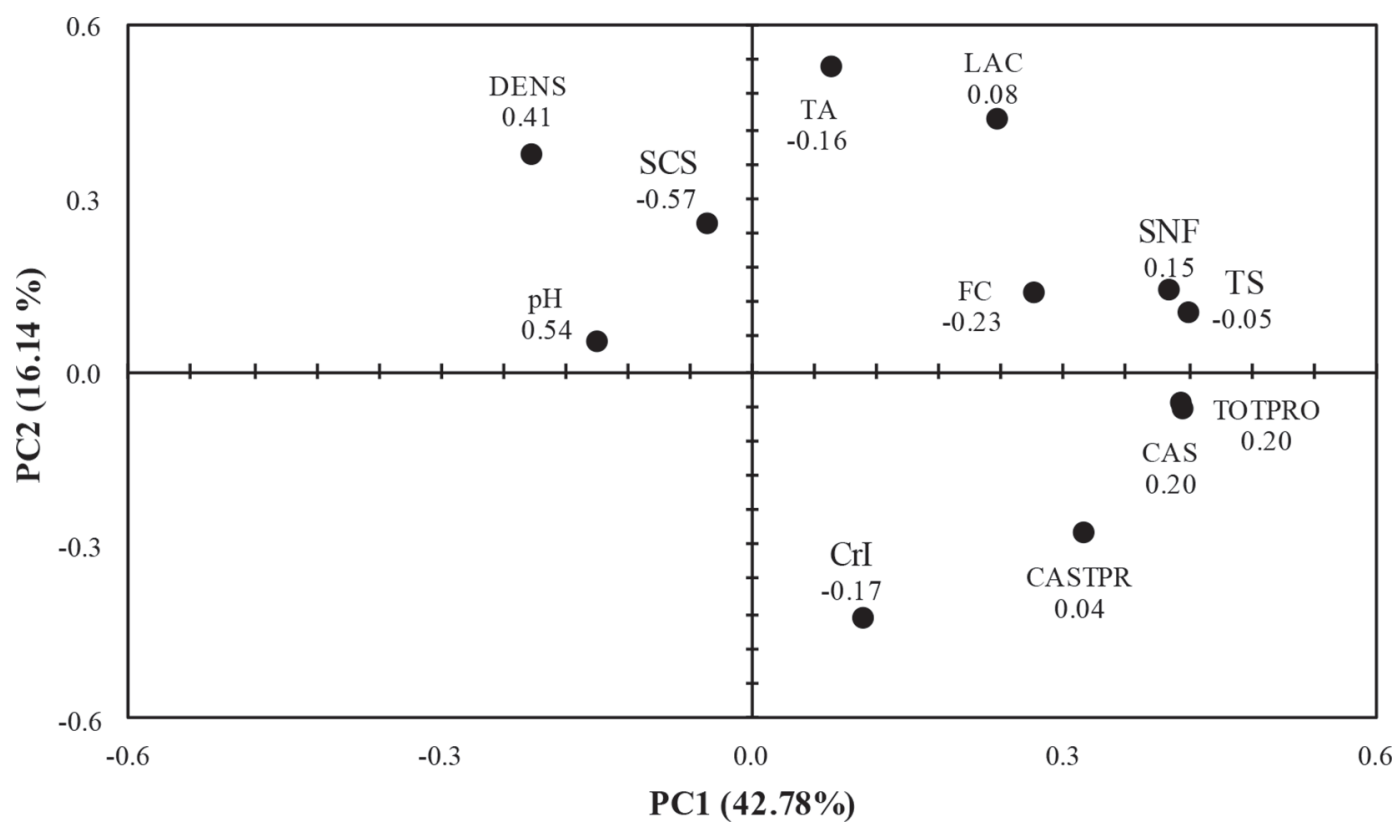

Figure 2. Graph of the principle component (PC) $1(42.78 \%)$ and $2(16.14 \%)$ scores, considering the group of milk composition variables. The coordinates of the third axis are recorded below the variable code. $\mathrm{FC}=$ fat content $(\%)$; TOTPRO = total protein content $(\%)$; CAS $=$ casein content (\%); CASTPR = casein:total protein ratio; LAC = lactose content (\%); TS = total solid content (\%); SNF = solids-not-fat content $(\%)$; DENS $=$ density at $15^{\circ} \mathrm{C}(\mathrm{g} / \mathrm{mL}) ; \mathrm{CrI}=$ cryoscopic index $\left({ }^{\circ}\right.$ Horvet $) ; \mathrm{TA}=$ titratable acidity $\left({ }^{\circ}\right.$ Dornic $) ; \mathrm{SCS}=\left[\log _{2}(\mathrm{SCC} / 100,000)\right.$ $+3],(\log$ cells $/ \mathrm{mL})$.

have a high negative and significant correlation with DENS $(P<0.05)$. Thus, in practice, the increase in the content of TOTPRO, CAS, and CASTPR relates to a decrease milk density, which in turn relates to a reduction of $\mathrm{pH}$ in the raw materials. Our results also confirm that reductions in $\mathrm{pH}$ will naturally increase the acidity, as they have a moderate correlation $(\mathrm{r}=$ -0.36 ), although it was not significant in the current study.
The CrI represents the temperature at which the substance freezes, and therefore it is used to detect fraud by adding water to the milk. It is worth noting that CrI is related to other factors, such as different levels of urea in milk, and also to the breed, lactation stage, and the diet quality of the animals (Matysek et al., 2011). The CrI presented a high to moderate positive correlation with protein and SNF constituents, different from that reported by Matysek et al. (2011),

Table 1. Descriptive statistics for physical and chemical characteristics of the milk used in mozzarella manufacturing

\begin{tabular}{|c|c|c|c|c|c|c|c|c|c|}
\hline \multirow[b]{2}{*}{ Variable $^{1}$} & \multicolumn{9}{|c|}{ Statistics $^{2}$} \\
\hline & Min & Mean & Mode & Med & Max & $\mathrm{CV}$ & $\mathrm{SD}$ & Skew & Kur \\
\hline $\mathrm{FC}$ & 5.73 & 6.10 & 6.00 & 6.14 & 6.40 & 2.87 & 0.17 & -0.44 & -0.42 \\
\hline TOTPRO & 3.52 & 3.80 & 3.60 & 3.81 & 4.16 & 4.21 & 0.16 & 0.10 & -0.52 \\
\hline CAS & 2.74 & 2.97 & 3.00 & 2.98 & 3.25 & 4.32 & 0.13 & 0.09 & -0.56 \\
\hline CASTPR & 77.78 & 78.07 & 78.13 & 78.08 & 78.41 & 0.18 & 0.14 & 0.24 & 0.37 \\
\hline $\mathrm{LAC}$ & 4.90 & 5.11 & 5.11 & 5.12 & 5.24 & 1.38 & 0.07 & -1.07 & 1.93 \\
\hline $\mathrm{TS}$ & 15.61 & 16.24 & 16.20 & 16.21 & 16.81 & 1.91 & 0.31 & -0.13 & -0.53 \\
\hline SNF & 9.70 & 10.15 & 10.17 & 10.17 & 10.51 & 2.04 & 0.21 & -0.38 & -0.48 \\
\hline DENS & $1,031.40$ & $1,032.91$ & $1,033.00$ & $1,033.00$ & $1,035.00$ & 0.08 & 0.86 & 0.51 & 0.22 \\
\hline CrI & 0.50 & 0.53 & 0.54 & 0.54 & 0.55 & 2.36 & 0.01 & -1.51 & 1.47 \\
\hline $\mathrm{pH}$ & 6.31 & 6.73 & 6.80 & 6.77 & 6.94 & 1.91 & 0.13 & -1.45 & 3.62 \\
\hline $\mathrm{TA}$ & 14.00 & 15.53 & 15.00 & 15.00 & 17.00 & 5.27 & 0.82 & 0.69 & -0.48 \\
\hline SCS & 0.90 & 0.99 & 1.03 & 1.02 & 1.05 & 5.55 & 0.06 & -0.71 & -1.20 \\
\hline
\end{tabular}

${ }^{1}$ Variables: $\mathrm{FC}=$ fat content (\%); TOTPRO = total protein content ( $\left.\%\right) ;$ CAS = casein content $(\%) ;$ CASTPR $=$ casein:total protein ratio; $\mathrm{LAC}=$ lactose content $(\%) ; \mathrm{TS}=$ total solid content $(\%) ; \mathrm{SNF}=$ solids-not-fat content $(\%) ; \mathrm{DENS}=$ density at $15^{\circ} \mathrm{C}(\mathrm{g} / \mathrm{mL}) ; \mathrm{CrI}=\mathrm{cryoscopic}$ index ( ${ }^{\circ}$ Horvet $) ; \mathrm{TA}=$ titratable acidity ( ${ }^{\circ}$ Dornic $) ; \mathrm{SCS}=\left[\log _{2}(\mathrm{SCC} / 100,000)+3\right],(\log$ cells $/ \mathrm{mL})$.

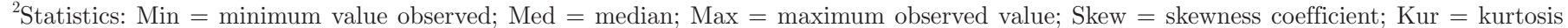
coefficient. 
MOZZARELLA YIELD AND MILK COMPOSITION RELATIONSHIP

Table 2. Pearson correlation between milk composition variables used in the manufacturing of mozzarella ${ }^{1}$

\begin{tabular}{|c|c|c|c|c|c|c|c|c|c|c|c|}
\hline Item & TOTPRO & CAS & CASTPR & LAC & TS & SNF & DENS & CrI & $\mathrm{pH}$ & TA & SCS \\
\hline TOTPRO & & $0.99 *$ & $0.61^{*}$ & 0.31 & $0.75^{*}$ & $0.91^{*}$ & $-0.42^{*}$ & 0.40 & -0.04 & -0.02 & -0.21 \\
\hline CAS & & & $0.64^{*}$ & 0.31 & $0.76^{*}$ & $0.91^{*}$ & $-0.44^{*}$ & 0.40 & -0.05 & -0.02 & -0.21 \\
\hline LAC & & & & & $0.48^{*}$ & $0.65^{*}$ & 0.17 & 0.00 & -0.02 & -0.12 & 0.30 \\
\hline $\mathrm{TS}$ & & & & & & $0.84^{*}$ & -0.37 & 0.23 & -0.17 & 0.09 & 0.15 \\
\hline SNF & & & & & & & -0.31 & 0.35 & -0.05 & -0.08 & -0.02 \\
\hline $\mathrm{pH}$ & & & & & & & & & & -0.36 & -0.22 \\
\hline TA & & & & & & & & & & & 0.10 \\
\hline
\end{tabular}

${ }^{1} \mathrm{FC}=$ fat content $(\%) ;$ TOTPRO $=$ total protein content $(\%) ; \mathrm{CAS}=$ casein content $(\%) ;$ CASTPR $=$ casein:total protein ratio; LAC $=$ lactose content (\%); TS = total solid content (\%); SNF = solids-not-fat content $(\%)$; DENS = density at $15^{\circ} \mathrm{C}(\mathrm{g} / \mathrm{mL}) ; \mathrm{CrI}=\mathrm{cryoscopic}$ index $\left({ }^{\circ}\right.$ Horvet $) ; \mathrm{TA}=$ titratable acidity $\left({ }^{\circ}\right.$ Dornic $) ; \mathrm{SCS}=\left[\log _{2}(\mathrm{SCC} / 100,000)+3\right],(\log$ cells $/ \mathrm{mL})$.

$* P<0.05$.

in which the decrease in CrI coincided with the increase in PROTTOT, FC, and TS levels of bovine milk.

The negative correlation between CrI and DENS was high and significant $(P<0.05)$. The freezing point and the density of all liquid substance is dependent on the dilution of solutes, with the former being influenced by the amount of dissolved solute (Fagnani et al., 2014) and the latter by the weight of the solution. In milk it is no different, as both the cryoscopy point and DENS have a dependent relationship with the dilution of chemical components, and therefore they are concomitantly altered.

The Pearson correlation coefficient between TA and $\mathrm{CrI}$ was high and significant $(P<0.05)$. In general, we observed that most of the correlations were negative and not significant. We noted a predominance of negative correlation between FC, TOTPRO, CAS, CASTPR, LAC, TS, and SNF versus DENS, PH, TA, and SCS, indicating that these 2 groups of variables have antagonistic behavior. On the other hand, we found a predominance of positive correlation between FC, TOTPRO, CAS, and TS with CASTPR, TS, and SNF. Significant correlation coefficients between SCS and physicochemical characteristics of milk were not found.

Principal Component Analysis Results. Considering the group of variables related to milk composition, the ratio of the variability explanation in the data of PC1, PC2, and PC3 were 42.78, 16.14, and $13.11 \%$, respectively, representing $72.02 \%$ of data variation (Figure 2). Variables located in the upper end of the $\mathrm{y}$-axis are those that have greater contribution to $\mathrm{PC} 1$ and are in contrast to the group of variables with a negative value in the same component. This means that solid contents (TS and SNF) of protein constituents (CAS, TOTPRO, and CASTPR) and FC are opposed to DENS and SCS. The $\mathrm{pH}$ is located closer to the intersection of the axes (0.0), demonstrating a steadier and less associated behavior in relation to others and being less important for the variability of the data.

These 12 milk composition variables can be summarized into 3 indexes, which explain $72.02 \%$ of the variability of the original data and can be used as new variables: index $1=0.4206 \mathrm{SNF}+0.4150 \mathrm{CAS}+\ldots-$ $0.0428 \mathrm{SCS}$; index $2=0.1030 \mathrm{SNF}-0.0638 \mathrm{CAS}+\ldots$ $+0.2572 \mathrm{SCS}$; and index $3=0.1451 \mathrm{SNF}+0.1957 \mathrm{CAS}$ $+\ldots-0.5745 \mathrm{SCS}$.

\section{Group 2: Processing Factors}

Descriptive Analysis. Descriptive statistics for the variables involved in the mozzarella manufacturing process are presented in Table 3. Skewness coefficients were only negative for VMILK, VCACL, and TCUTS. Kurtosis coefficients were positive for VMILK, PHSC, SCAC, ASC, VSC, VCACL, VRE, and COT. The results show that the distribution of these variables is sharper or more pronounced (having fatter tails, leptokurtic) than normal, with the strongest peak for VMILK, ASC, VCACL, VRE, and COT. Thus, these 5 variables have most of their frequencies closer to the means.

The relationship between the processing variables from closer to normal to more distant are FERM2T, PHSC, STRT, VSC, PHCU, FERM1T, TCUTS, SCAC, VCACL, VMILK, ASC, TEMPRE, COT, and VRE. The dairy industry tries to keep these last 6 variables at uniform levels to ensure standardization in milk processing and product quality. Thus, they suffer greater human control in relation to others throughout mozzarella processing, and their values tend to be more homogeneous in relation to other variables associated with the manufacturing process. Therefore, they had a very distinct frequency distribution from the normal.

Pearson Correlation Analysis. The variables in Table 2 have a very close relationship due to their 
origin and milk composition. The variables in Table 4 are involved in the process of cheese manufacturing, are moderately correlated, and have different characteristics, especially in the way they relate to the manufacturing process. For example, PHSC, SCAC, ASC, and VSC are intrinsic aspects of the starter culture (natural whey culture), whereas VCACL and VRE are aspects of other ingredients used in the processing and the remaining variables are process conditions themselves, representing mass and time aspects between and during steps. Perhaps this is why most of the correlations were not significant and varied from weak positive $(0.20$ to $0.29)$ to moderate positive $(0.30$ to 0.29$)$, indicating independence between variables, although they are necessary and important in the mozzarella manufacturing process.

In general, the volume of ingredients relates to the volume of milk used for the production of (each) cheese batch. Thus, the high correlation coefficients between VMILK and the VCACL and VRE variables are justified. However, the reason for the inverse relationship between VMILK and VCACL and VRE is uncertain, as well as the significance between ASC and VMILK, which are completely independent variables.

High positive and negative correlation $(P<0.05)$ of VRE with VMILK and with COT were found, respectively. As rennet is added at a ratio of $1 \mathrm{~g}$ for every 100 $\mathrm{L}$ of milk, it is expected that the VRE has a positive correlation with the amount of milk employed in the process, as the enzymes of the curd promote milk clotting and the speed for obtaining the curd is greater when there is a higher amount of this ingredient; however, we did not observe a positive correlation. The highest correlation coefficient was found between VSC and SCAC $(-0.79 ; P<0.05)$.

In fact, the recommendation followed by the dairy plant required starter culture volume to be added in the production of mozzarella based on the acidity of this ingredient at that moment, considering that the higher the SCAC, the greater the lactic acid concentration of the whey. Consequently, the greater its ability to increase acidity of the medium, the less of this ingredient added.

In addition to COT, the times (in minutes) during the process steps are represented by the variables TCUTS, FERM1T, FERM2T, and STRT.

Both TCUTS and STRT are variables that, in practice, are independent from the others, although STRT depends on the volume of curd produced and therefore of the amount of milk used (VMILK). Nevertheless, as some standardization occurred in terms of the amount of milk used in the accompanied batches (about 750 $\mathrm{L} /$ batch), the variation of curd produced was low and STRT showed no significant correlation with VMILK of the batches.

The STRT is directly correlated with PHSC and ASC $(P<0.05)$ due to the condition that the starter culture can confer to the cheese curd. Higher PHSC impairs acidification and stretching of the curd, as mozzarella curd with impaired acidity does not easily bind to water during stretching, having little elasticity and breaking easily (Altiero et al., 1984). This may delay

Table 3. Descriptive statistics for the variables involved in the mozzarella manufacturing process

\begin{tabular}{|c|c|c|c|c|c|c|c|c|c|}
\hline \multirow[b]{2}{*}{ Variable $^{1}$} & \multicolumn{9}{|c|}{ Statistics $^{2}$} \\
\hline & Min & Mean & Mode & Med & $\operatorname{Max}$ & $\mathrm{CV}$ & $\mathrm{SD}$ & Skew & Kur \\
\hline VMILK & 641.13 & 738.04 & 739.01 & 739.01 & 797.74 & 3.59 & 26.52 & -1.07 & 6.64 \\
\hline PHSC & 3.42 & 4.05 & 4.05 & 4.03 & 4.82 & 8.28 & 0.34 & 0.29 & 0.09 \\
\hline SCAC & 58.00 & 75.00 & 78.69 & 75.00 & 115.00 & 18.23 & 14.54 & 0.97 & 0.28 \\
\hline $\mathrm{ASC}$ & 12.00 & 37.48 & 36.00 & 36.00 & 84.00 & 47.09 & 17.63 & 1.30 & 2.19 \\
\hline VSC & 19.00 & 35.86 & 30.00 & 34.00 & 50.00 & 21.34 & 7.54 & 0.03 & 0.09 \\
\hline VCACL & 28.20 & 30.43 & 30.45 & 30.45 & 31.97 & 2.13 & 0.65 & -0.74 & 5.02 \\
\hline VRE & 1.34 & 1.48 & 1.49 & 1.49 & 1.72 & 4.33 & 0.06 & 1.08 & 6.39 \\
\hline TEMPRE & 37.00 & 37.28 & 37.27 & 37.00 & 38.00 & 1.25 & 0.47 & 0.92 & -1.24 \\
\hline PHCU & 4.79 & 5.02 & 4.79 & 5.02 & 5.40 & 3.20 & 0.16 & 0.36 & -0.17 \\
\hline COT & 10.00 & 15.34 & 15.00 & 15.00 & 20.00 & 11.90 & 1.83 & 0.86 & 5.06 \\
\hline TCUTS & 30.00 & 48.52 & 46.00 & 49.50 & 66.00 & 20.55 & 10.02 & -0.22 & -0.54 \\
\hline FERM1T & 103.00 & 165.86 & 190.00 & 157.50 & 240.00 & 20.29 & 33.53 & 0.11 & -0.36 \\
\hline STRT & 34.00 & 45.45 & 40.00 & 45.00 & 59.00 & 15.18 & 6.92 & 0.22 & -0.60 \\
\hline FERM2T & 200.00 & 266.93 & 250.00 & 262.00 & 340.00 & 12.05 & 32.10 & 0.14 & -0.05 \\
\hline
\end{tabular}

\footnotetext{
${ }^{1}$ Variables: VMILK $=$ volume of milk used (L); PHSC $=$ pH of starter culture; SCAC = starter culture acidity $\left({ }^{\circ}\right.$ Dornic); ASC $=$ age of the

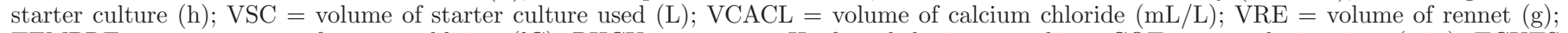

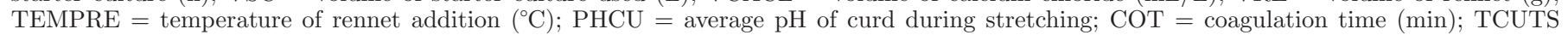

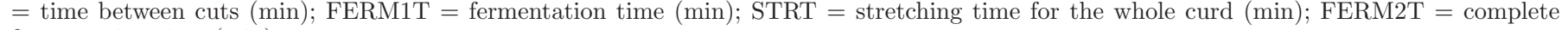
fermentation time (min).

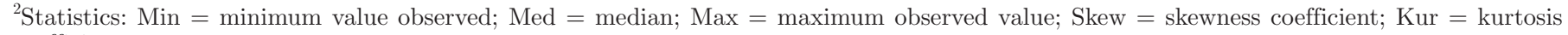
coefficient.
} 
the duration of the stretching step. Increased STRT with increase in ASC may be associated with lower acidifying contribution from a starter culture with advanced age.

Fermentation control during mozzarella manufacturing is essential to ensure good conditions for the curd in terms of acidification for good stretching. The curd is fermenting from the end of the milk coagulation until its stretching, a period comprising the FERM2T. The importance of tracking FERM2T is more to assist in adjusting the processing time. The FERM1T comprises the time period between curd cutting until its removal from the production tank. The cheesemaker observes the behavior of the curd's $\mathrm{pH}$ in the tank until it reaches the ideal point of stretching, and then the curd is separated from the whey avoiding rapid fermentation advancement. As FERM1T is part of the steps that occur concomitantly with some steps of FERM2T, a dependent relationship exists between these variables in a way that they maintain strong positive correlation $(0.77 ; P<0.05)$.

After the curd is cut, it is more exposed to the whey so that the acidity of these 2 products tends to become more similar with fermentation advancement, which occurs during FERM1T. No clear reason for the occurrence of moderate positive correlation between ASC and FERM1T exists; however, a starter culture with higher ASC can have its acidifying power diminished, which may impair the acidification of the curd, thus increasing FERM1T and consequently FERM2T, which are highly correlated $(P<0.05)$. Although a significant correlation between FERM1T and the TCUTS has been observed, they are completely independent factors.

Principal Component Analysis Results. The proportion of explained variability of $\mathrm{PC} 1, \mathrm{PC} 2$, and PC3 for the group of mozzarella manufacturing process variables was $23.74,21.42$, and $14.23 \%$, respectively, in such a way that the 3 components explained $59.39 \%$ of the data variation (Figure 3). The variables that have the greatest contribution to PC1 are located at the upper end of the graph, and they are contrasted by the group of variables with a negative value in the same component. Therefore, the fermentation times (FERM1T and FERM2T) and curd cut (TCUTS), and the age (ASC) and acidity (SCAC) conditions of the starter culture have an opposite association with VMILK and VSC used in the manufacture and milk coagulation conditions (COT and TEMPRE). Both PHSC and STRT are located closer to the intersection of the axes (0.0), demonstrating a more constant and less associated behavior in relation to others, being less important for the variability of the data.

The 14 variables related to the cheesemaking process can be summarized into 3 indexes, which explain 


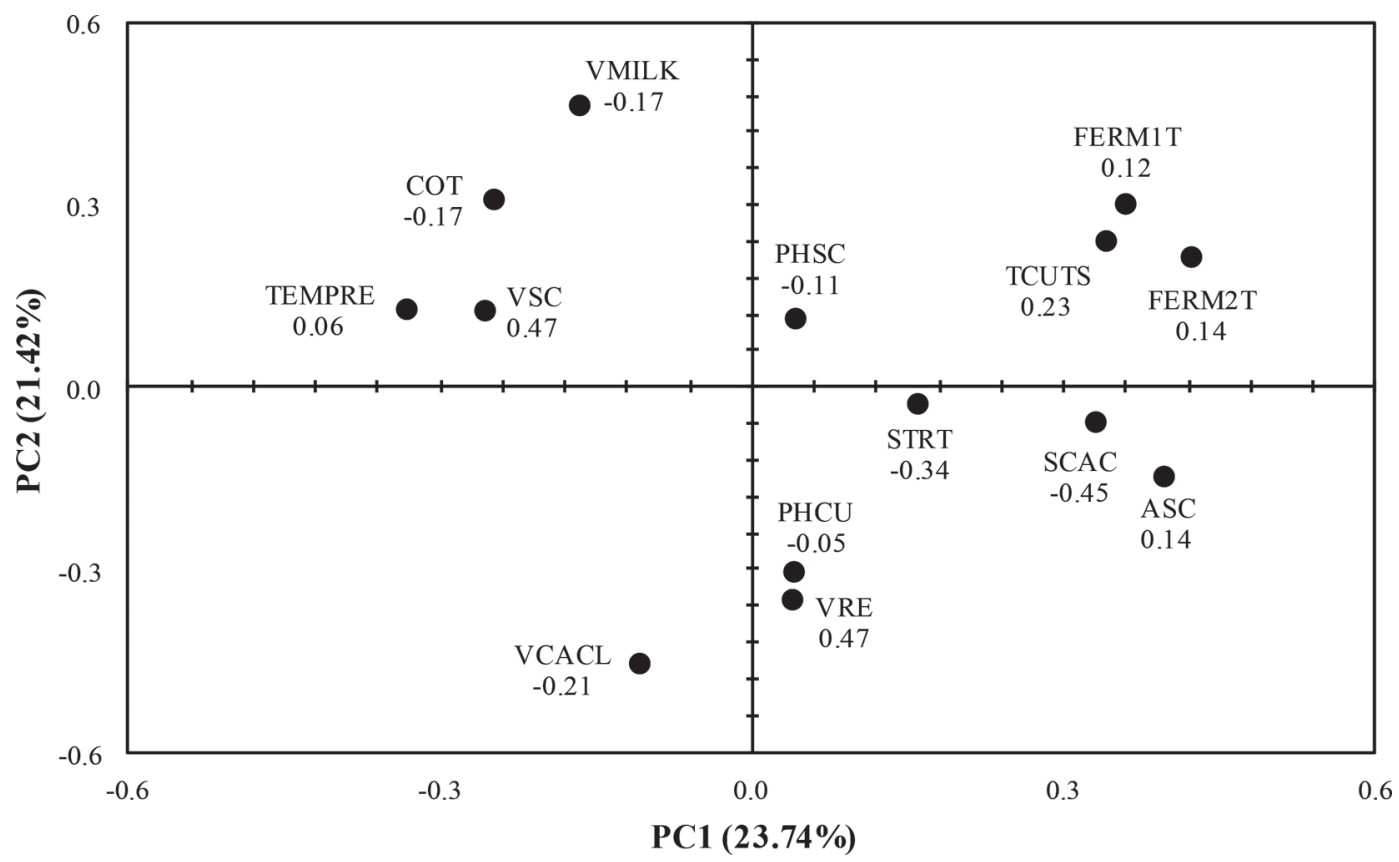

Figure 3. Graph of the principle component (PC) 1 (23.74\%) and 2 (21.42\%) scores, considering the group of mozzarella manufacturing process variables. The coordinates of the third axis are recorded below the variable code. VMILK $=$ volume of milk used $(\mathrm{L})$; $\mathrm{PHSC}=\mathrm{pH}$ of starter culture; $\mathrm{SCAC}=$ starter culture acidity $\left({ }^{\circ}\right.$ Dornic); $\mathrm{ASC}=$ age of the starter culture $(\mathrm{h})$; VSC = volume of starter culture used (L); $\mathrm{VCACL}=$ volume of calcium chloride $(\mathrm{mL} / \mathrm{L})$; VRE $=$ volume of rennet $(\mathrm{g})$; TEMPRE $=$ temperature of rennet addition $\left({ }^{\circ} \mathrm{C}\right) ; \mathrm{PHCU}=$ average $\mathrm{pH}$ of curd during stretching; COT = coagulation time $(\mathrm{min})$; TCUTS = time between cuts (min); FERM1T = fermentation time (min); $\mathrm{STRT}=$ stretching time for the whole curd $(\mathrm{min}) ; \mathrm{FERM} 2 \mathrm{~T}=$ complete fermentation time $(\mathrm{min})$.

$59.39 \%$ of the variability of the original data and can be used as new variables: index $1=0.4234 \mathrm{FERM} 2 \mathrm{~T}+$ $0.3971 \mathrm{ASC}+\ldots+0.0395 \mathrm{VRE}$; index $2=0.2153 \mathrm{FER}-$ $\mathrm{M} 2 \mathrm{~T}-0.1461 \mathrm{ASC}+\ldots-0.3489 \mathrm{VRE}$; and index 3 $=0.1416 \mathrm{FERM} 2 \mathrm{~T}+0.1427 \mathrm{ASC}+\ldots+0.4728 \mathrm{VRE}$.

\section{Group 3: Recovery of Whey Constituents}

Descriptive Analysis. Descriptive statistics for the recovery of whey constituent (RWC) and MY variables are presented in Table 5. The relationship of the closest variables of the normal distribution to the most distant are MY, FATREC, LACREC, TSREC, SNFREC, CASREC, and PROTREC. Only FATREC and MY showed a positive skewness and kurtosis below zero, and, in practice, protein and casein recovery in whey tend to be more stable in comparison to the other variables.

Pearson Correlation Analysis. Regarding the correlation between FATREC, PROTREC, CASREC, LACREC, TSREC, and SNFREC percentages in whey,

Table 5. Descriptive statistics for the recovery of whey constituent and mozzarella yield variables

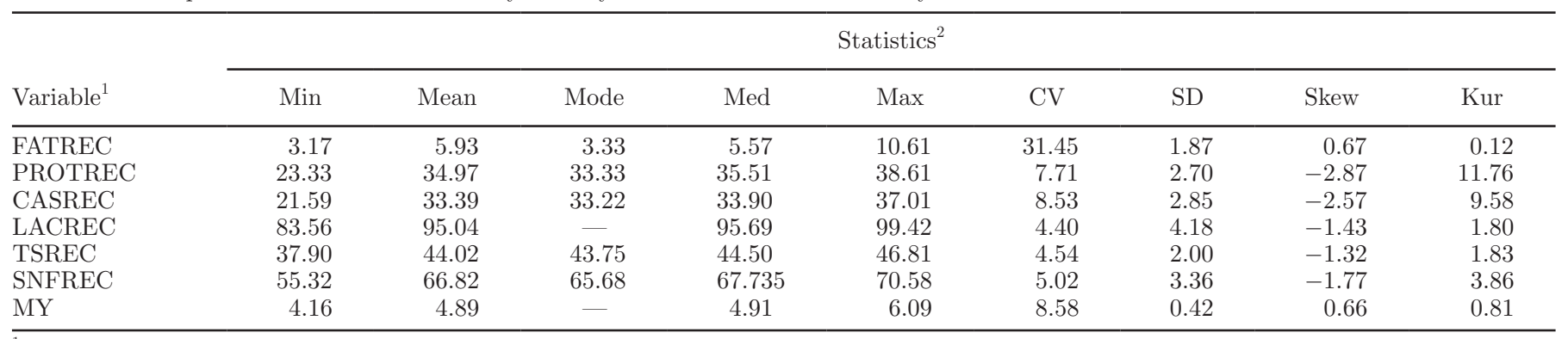

${ }^{1}$ Variables: FATREC $=$ fat recovery from whey $(\%)$ PROTREC $=$ protein recovery from whey $(\%)$; CASREC = casein recovery from whey $(\%) ;$ LACREC $=$ lactose recovery from whey $(\%)$; TSREC $=$ total solids recovery from whey $(\%)$; SNFREC = solids-not-fat recovery from whey $(\%) ; \mathrm{MY}=$ mozzarella yield $(\mathrm{kg} / \mathrm{kg})$.

${ }^{2}$ Statistics: Min = minimum value observed; Med = median; Max $=$ maximum observed value; Skew $=$ skewness coefficient; Kur $=$ kurtosis coefficient. 
Table 6. Pearson correlation between recovery of whey constituent (RWC) variables in mozzarella ${ }^{1}$

\begin{tabular}{lccccc}
\hline Item & PROTREC & CASREC & LACREC & TSREC & SNFREC \\
\hline FATREC & $-0.41^{*}$ & $-0.41^{*}$ & -0.15 & 0.03 & -0.24 \\
PROTREC & & $0.98^{*}$ & $0.75^{*}$ & $0.71^{*}$ & $0.86^{*}$ \\
CASREC & & $0.72^{*}$ & $0.66^{*}$ & $0.82^{*}$ \\
LACREC & & & $0.91^{*}$ & $0.94^{*}$ \\
TSREC & & & & $0.94^{*}$ \\
\hline
\end{tabular}

${ }^{1}$ FATREC $=$ fat recovery from whey $(\%)$; PROTREC $=$ protein recovery from whey $(\%)$; CASREC $=$ casein recovery from whey $(\%)$; LACREC $=$ lactose recovery from whey $(\%)$; TSREC $=$ total solids recovery from whey $(\%)$; SNFREC $=$ solids-not-fat recovery from whey $(\%)$.

${ }^{*} P<0.05$.

Table 6 shows that these variables were almost all correlated, indicating their dependence and importance in this study. In general, their correlation was higher than the other studied variables (Tables 2, 4 and 5), indicating that RWC variables are more related.

Lactose and fat are the 2 main solids recovered in whey (larger RWC), and therefore LACREC, PROTREC, and CASREC have a strong positive relationship with TSREC $(P<0.05)$. This same relationship is seen among these 4 variables and SNFREC $(P<0.05)$, as all the solids recovered in whey comprise milk SNF, with the exception of fat.

Principal Component Analysis Results. For the recovery of whey constituents' variables, the ratio of the explained variability in $\mathrm{PC} 1, \mathrm{PC} 2$, and $\mathrm{PC} 3$ was 73.36, 19.06, and $0.06 \%$, respectively, totaling $98.16 \%$. The components almost explained the entire data, indicating that this group of 6 original variables can be reduced to only 3 new variables in a representative manner. The SNFREC, PROTREC, LACREC, CASREC, and SNFREC variables are those that have greater contribution to PC1 (Figure 4), and this can be explained by the high positive correlation among them (Table 5). The CASREC is highly associated wih PROTREC, indicating that protein losses in whey are closely associated with casein losses. The arrangement of the variables shows that solid losses (total and nonfat) are strongly associated with lactose and little associated with fat, protein, and casein. In fact, lactose is the least used milk nutrient in cheese production, and therefore the one with the highest losses compared with other (nutrients).

The 5 variables of this group can be summarized in 3 indexes or variables: index $1=0.4664 \mathrm{SNFREC}+\ldots$

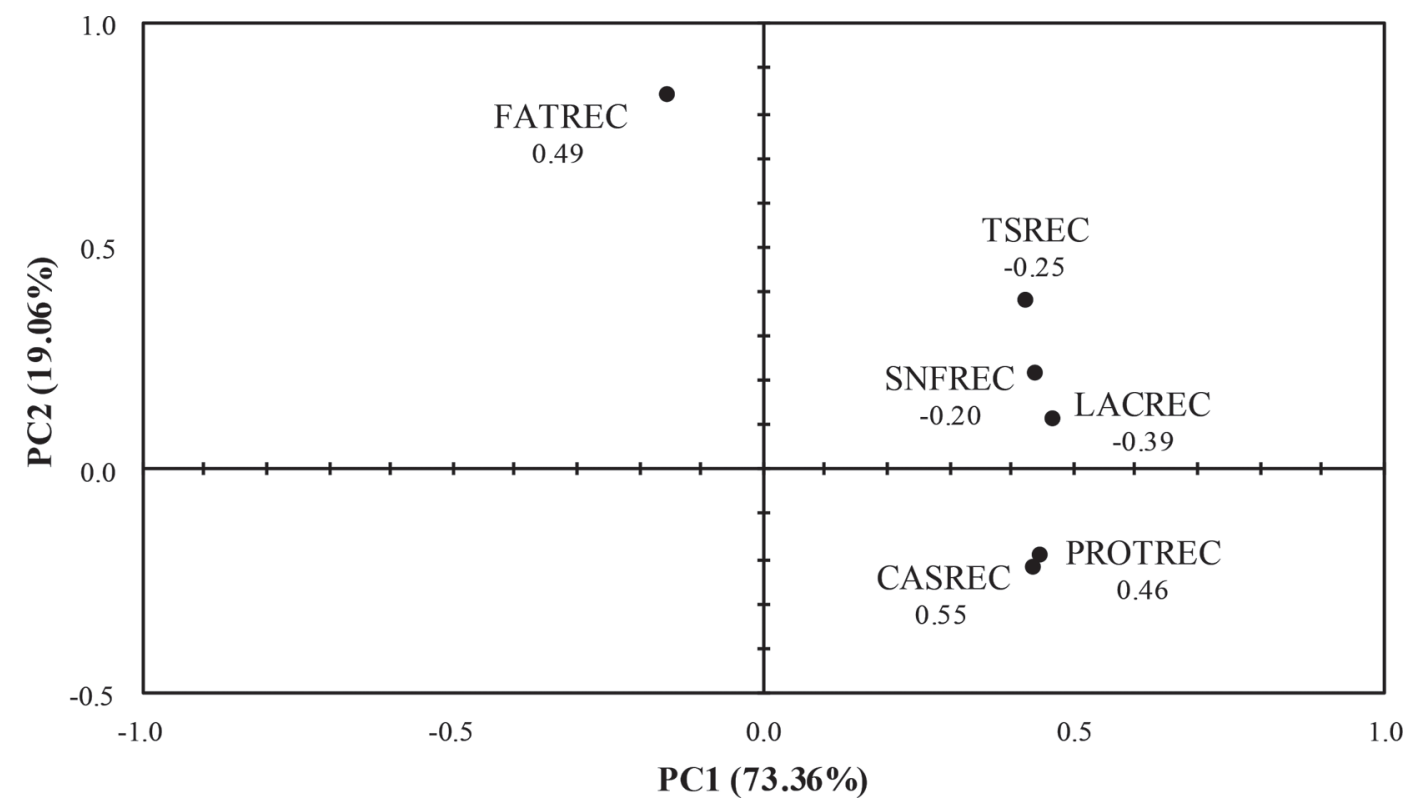

Figure 4. Graph of the principle components (PC) $1(73.36 \%)$ and $2(19.06 \%)$ considering the group of recovery of whey constituents variables. The coordinates of the third axis are recorded below the variable code. FATREC $=$ fat recovery from whey $(\%)$; PROTREC $=$ protein recovery from whey $(\%)$; CASREC $=$ casein recovery from whey $(\%)$; LACREC = lactose recovery from whey $(\%)$; TSREC $=$ total solids recovery from whey $(\%)$; SNFREC = solids-not-fat recovery from whey $(\%)$. 
-0.1548 FATREC; index $2=0.1152$ SNFREC $+\ldots$ +0.8427 FATREC; and index $3=-0.1951$ SNFREC $+\ldots+0.4852$ FATREC.

\section{Relationship Between MY, Milk Composition, Processing Factors, and Recovery of Whey}

As the aim of this study was to identify the relationship between yield and the variables of milk composition, processing, and recovery of whey constituents through multivariate analysis. We calculated the correlation between these variables and MY. The Pearson correlation coefficients (r) for all variables of the current study are presented in Table 7 in descending order of magnitude. Of the 33 variables, only 2 had significant Pearson correlation coefficient $(P<0.05)$ with MY, namely TCUTS and ASC. Most of the study variables were weakly correlated with MY.

By studying yield, it is interesting understand the efficiency in using milk in the perception of this material for manufacturing mozzarella (Sales et al., 2016); hence, correlation coefficients that favor decreased variable MY (quantity of milk used per kilogram of cheese produced) are more relevant. According to this logic (to a moderate degree), the decrease in MY is favored by an increase in COT $(P<0.05)$ and with the decrease of TCUTS and ASC $(P<0.05)$. Likewise, a theoretical increase of the remaining variables with negative correlation coefficient and decrease of those that have positive correlation coefficient is favored.

Ahmed et al. (2011) identified the effect of different coagulants on chemical composition and on mozzarella cheese curd yield. We observed that VRE and TOC had a high correlation between each other $(-0.41, P$ $<0.05)$ and with MY (0.27 and -0.36, $P>0.05)$. Thus, the type and volume of the coagulant and the coagulation conditions are in fact relevant for the quality and quantity of mozzarella cheese (Abd El-Gawad and Ahmed, 2011).

Unlike our results, Cipolat-Gotet et al. (2015), using individual samples of buffalo milk, observed that the curd yield had high and significant correlation with TS (0.90), FC (0.85), TOTPRO (0.75), CAS (0.78), and TSREC (0.90) and moderate and significant correlation with LAC (-0.29), PROTREC (0.40), and FATREC (0.31).

In spite of the lack of expressiveness of correlation coefficient related to RWC in the current research, Cecchinato and Bittante (2016) demonstrated that protein recovery is strongly related to cheese yield through a detailed study on the relationship between milk coagulation properties, the recovery of constituents, and the cheese yield. Therefore, PROTREC is an important element to consider when seeking to improve cheese manufacturing efficiency.

A significant correlation between yield and TSREC, PROTREC, FATREC, LACREC, and SNFREC were not found. However, in terms of a favorable reduction to MY, the values of the positive correlation for RWC follow the logic indicated in the literature, with the exception of PROTREC and CASREC.

Table 7. Pearson correlation of milk composition, processing, and recovery of whey constituent variables to mozzarella yield (MY; kg/ $\mathrm{kg})$

\begin{tabular}{lc}
\hline Variable $^{1}$ & MY \\
\hline TCUTS & $0.38^{*}$ \\
ASC & $0.36^{*}$ \\
COT & -0.36 \\
CASTPR & 0.28 \\
CAS & 0.28 \\
TOTPRO & 0.28 \\
STRT & 0.27 \\
VRE & 0.27 \\
FC & -0.26 \\
CrI & -0.26 \\
VMILK & -0.25 \\
SNF & 0.24 \\
pH & 0.21 \\
DENS & -0.21 \\
LACREC & 0.20 \\
TSREC & 0.19 \\
VSC & 0.18 \\
CASREC & -0.17 \\
VCACL & -0.14 \\
LAC & 0.12 \\
PROTREC & -0.12 \\
SCS & -0.12 \\
SCAC & -0.12 \\
FATREC & 0.09 \\
PHSC & 0.09 \\
PHCU & 0.08 \\
SNFREC & 0.06 \\
FERM1T & -0.06 \\
TEMPRE & 0.05 \\
FERM2T & 0.05 \\
TA & -0.04 \\
TS & 0.02 \\
I & \\
\hline
\end{tabular}

${ }^{1}$ TCUTS $=$ time between cuts $(\mathrm{min}) ; \mathrm{ASC}=$ age of the starter culture (h); COT $=$ coagulation time $(\min ) ;$ CASTPR $=$ casein:total protein ratio; CAS $=$ casein content $(\%)$; TOTPRO $=$ total protein content $(\%) ;$ STRT $=$ stretching time for the whole curd (min); VRE = volume of rennet $(\mathrm{g}) ; \mathrm{FC}=$ fat content $(\%) ; \mathrm{CrI}=$ cryoscopic index $\left(^{\circ}\right.$ Horvet); VMILK $=$ volume of milk used (L); SNF = solids-not-fat content $(\%)$; DENS $=$ density at $15^{\circ} \mathrm{C}(\mathrm{g} / \mathrm{mL})$; LACREC $=$ lactose recovery from whey $(\%)$; TSREC $=$ total solids recovery from whey $(\%)$; $\mathrm{VSC}=$ volume of starter culture used $(\mathrm{L}) ; \mathrm{CASREC}=$ casein recovery from whey $(\%)$; VCACL $=$ volume of calcium chloride $(\mathrm{mL} / \mathrm{L}) ; \mathrm{LAC}$ $=$ lactose content $(\%)$; PROTREC $=$ protein recovery from whey $(\%)$; $\mathrm{SCS}=\left[\log _{2}[\mathrm{SCC} / 100,000)+3\right],(\log$ cells $/ \mathrm{mL}) ; \mathrm{SCAC}=$ starter culture acidity $\left({ }^{\circ}\right.$ Dornic); FATREC $=$ fat recovery from whey $(\%)$; PHSC $=\mathrm{pH}$ of starter culture; $\mathrm{PHCU}=$ average $\mathrm{pH}$ of curd during stretching; SNFREC = solids-not-fat recovery from whey (\%); FERM1T = fermentation time $(\mathrm{min})$; TEMPRE $=$ temperature of rennet addition $\left({ }^{\circ} \mathrm{C}\right) ;$ FERM2T $=$ complete fermentation time $(\mathrm{min}) ; \mathrm{TA}=$ titratable acidity $\left({ }^{\circ}\right.$ Dornic); TS $=$ total solid content $(\%)$.

$* P<0.05$. 
Figure 5 shows PC1 versus PC2 scores for the 33 variables in the current study. The explained variability of each component was $26.37,17.38$, and $12.44 \%$, respectively, totaling $56.18 \%$.

In the group of moderate- to high-weight variables in PC1 and PC2, a direct association between milk characteristics (TS, SNF, CAS, TOTPRO, CASTPR, FC, and TA) and FATREC was observed, as well as an antagonistic association between those variables and MY, pH and DENS, FERM1T, and ASC. This means that MY is lower (low kilograms of milk-to-kilograms of cheese ratio, which is desirable) when using buffalo milk with higher concentrations of TS, SNF, CAS, TOTPRO, CASTPR, and FC and when there is greater loss of FC in whey (FATREC).

However, as the result of the principal component analysis shows a proximity between CAS and FATREC and an antagonism between them and MY, in batches of cheese produced with milk containing higher concentrations of casein we found no significant loss of yield, even with low utilization of fat in the curd. This can be explained by the fact that casein is crucial for curd structuring and retention of other constituents, which can compensate for fat losses (Abd El-Gawad and Ahmed, 2011). In addition to this compensation, a large part of milk fat usually participates in the constitution of mozzarella, as its loss reaches just under $6 \%$ in whey (Table 5).

Milk fat and protein (casein) are the main contributors to the cheese curd; the formation properties, curd curing and syneresis are highly dependent on milk composition (Abd El-Gawad and Ahmed, 2011; Cecchinato and Bittante, 2016; Sales et al., 2016). Moreover, fermentation conditions of the curd (FERM1T) and the amount of cheese produced (MY) are also strongly influenced by milk composition (Figure 5).

Observing the group of moderate- to high-weight variables in $\mathrm{PC} 2$, a direct association can be found between those representing the loss of nonfat constituents in whey (CASREC, PROTREC, and LACREC) and SCS. This means that, in manufacturing mozzarella from batches of milk with lower SCS, there is greater

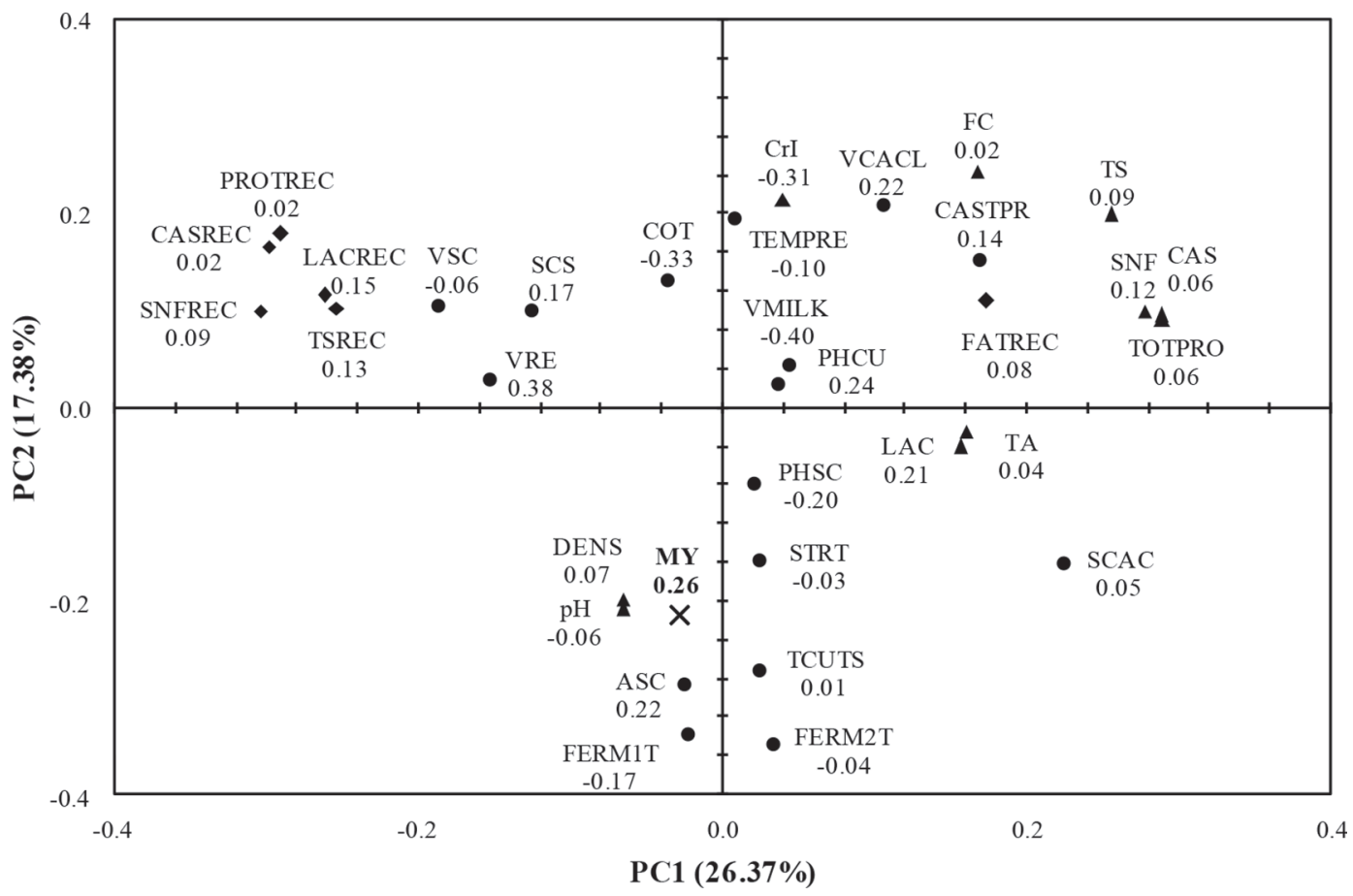

Figure 5. Graph of the principle components (PC) $1(26.37 \%)$ and $2(17.38 \%)$, considering mozzarella yield $(\times)$, milk composition $(\mathbf{\Lambda})$, processing $(\bullet)$, and recovery of whey constituents variables $(-)$. The coordinates of the third axis are recorded below the variable code. MY $=$ mozzarella yield $(\mathrm{kg} / \mathrm{kg}) ; \mathrm{FC}=$ fat content (\%); TOTPRO = total protein content (\%); CAS = casein content (\%); CASTPR = casein:total protein ratio; LAC = lactose content $(\%) ; \mathrm{TS}=$ total solid content $(\%) ; \mathrm{SNF}=$ solids-not-fat content $(\%) ; \mathrm{DENS}=\mathrm{density}$ at $15^{\circ} \mathrm{C}(\mathrm{g} / \mathrm{mL}) ; \mathrm{CrI}$ $=$ cryoscopic index $\left({ }^{\circ}\right.$ Horvet $) ; \mathrm{TA}=$ titratable acidity $\left({ }^{\circ}\right.$ Dornic $) ; \mathrm{SCS}=\left[\log _{2}(\mathrm{SCC} / 100,000)+3\right],(\log$ cells $/ \mathrm{mL}) ; \mathrm{VMILK}=$ volume of milk used $(\mathrm{L}) ; \mathrm{PHSC}=\mathrm{pH}$ of starter culture; $\mathrm{SCAC}=$ starter culture acidity $\left({ }^{\circ}\right.$ Dornic $)$; ASC $=$ age of the starter culture $(\mathrm{h})$; VSC $=$ volume of starter culture used $(\mathrm{L}) ; \mathrm{VCACL}=$ volume of calcium chloride $(\mathrm{mL} / \mathrm{L}) ; \mathrm{VRE}=$ volume of rennet $(\mathrm{g})$; TEMPRE $=$ temperature of rennet addition $\left({ }^{\circ} \mathrm{C}\right)$; $\mathrm{PHCU}=$ average $\mathrm{pH}$ of curd during stretching; COT $=$ coagulation time $(\mathrm{min})$; TCUTS $=$ time between cuts $(\min ) ; \mathrm{FERM1T}=$ fermentation time $(\mathrm{min}) ; \mathrm{STRT}=$ stretching time for the whole curd $(\mathrm{min}) ; \mathrm{FERM} 2 \mathrm{~T}=$ complete fermentation time $(\mathrm{min}) ; \mathrm{FATREC}=$ fat recovery from whey (\%); PROTREC = protein recovery from whey (\%); CASREC = casein recovery from whey (\%); LACREC = lactose recovery from whey $(\%)$ TSREC $=$ total solids recovery from whey $(\%)$; SNFREC = solids-not-fat recovery from whey $(\%)$. 


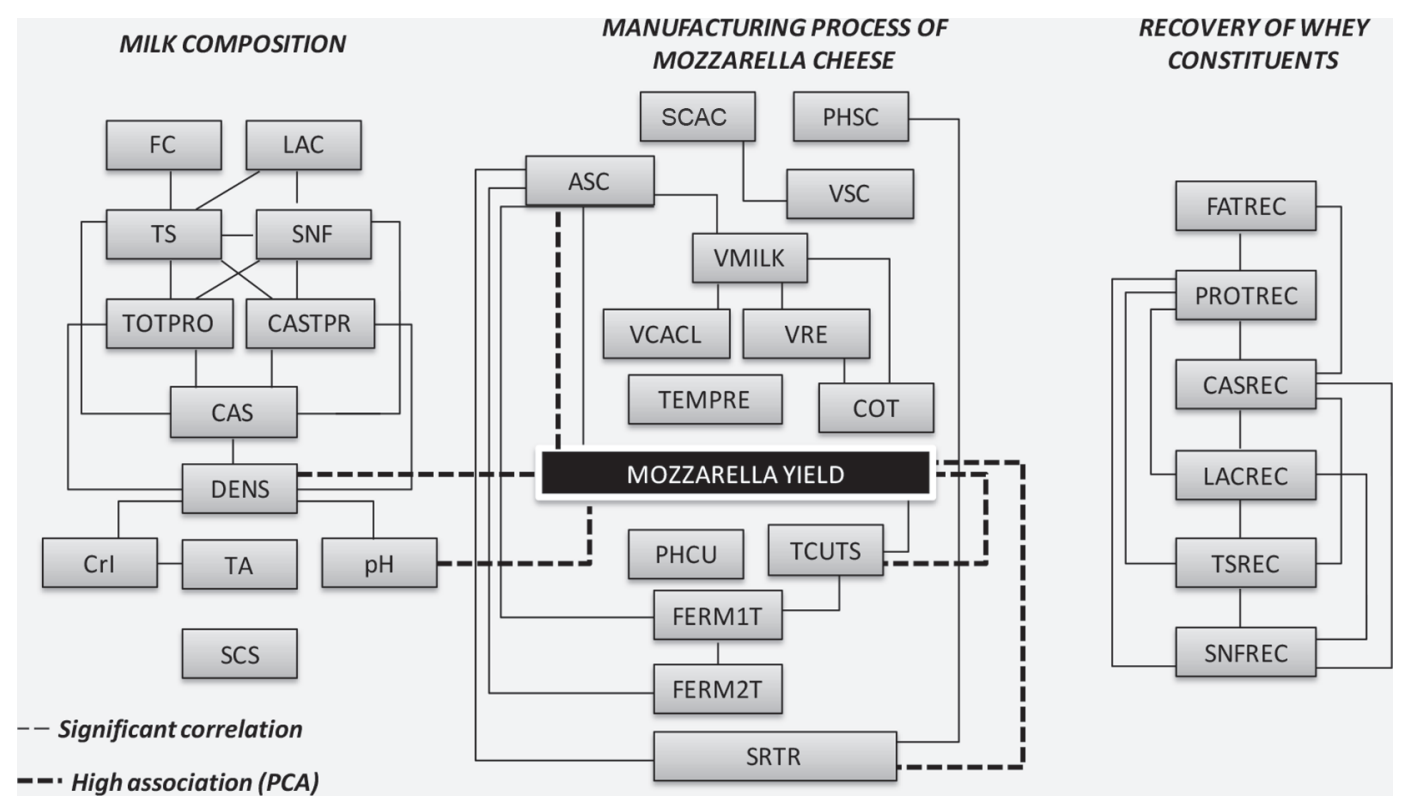

Figure 6. Summary scheme of the relationship between variables of milk composition, processing, and recovery of whey constituents; and between them and mozzarella yield. $\mathrm{MY}=$ mozzarella yield $(\mathrm{kg} / \mathrm{kg}) ; \mathrm{FC}=$ fat content $(\%)$; TOTPRO = total protein content $(\%)$; $\mathrm{CAS}=$ casein content (\%); CASTPR = casein:total protein ratio; LAC = lactose content (\%); TS = total solid content (\%); SNF = solids-not-fat content (\%); DENS = density at $15^{\circ} \mathrm{C}(\mathrm{g} / \mathrm{mL}) ; \mathrm{CrI}=$ cryoscopic index $\left({ }^{\circ}\right.$ Horvet $) ; \mathrm{TA}=$ titratable acidity $\left({ }^{\circ}\right.$ Dornic $) ; \mathrm{SCS}=\left[\log _{2}(\mathrm{SCC} / 100,000)\right.$ $+3],(\log$ cells $/ \mathrm{mL}) ; \mathrm{VMILK}=$ volume of milk used $(\mathrm{L}) ; \mathrm{PHSC}=\mathrm{pH}$ of starter culture; $\mathrm{SCAC}=$ starter culture acidity $\left({ }^{\circ}\right.$ Dornic $) ;$ ASC $=$ age of the starter culture $(\mathrm{h}) ; \mathrm{VSC}=$ volume of starter culture used $(\mathrm{L}) ; \mathrm{VCACL}=$ volume of calcium chloride $(\mathrm{mL} / \mathrm{L}) ; \mathrm{VRE}=$ volume of rennet $(\mathrm{g})$; TEMPRE = temperature of rennet addition $\left({ }^{\circ} \mathrm{C}\right)$; PHCU $=$ average $\mathrm{pH}$ of curd during stretching; COT = coagulation time $($ min $)$; TCUTS $=$ time between cuts $(\mathrm{min}) ; \mathrm{FERM} 1 \mathrm{~T}=$ fermentation time $(\mathrm{min}) ; \mathrm{STRT}=$ stretching time for the whole curd $(\mathrm{min})$; FERM2T $=$ complete fermentation time ( $\mathrm{min})$; FATREC $=$ fat recovery from whey (\%); PROTREC = protein recovery from whey $(\%)$; CASREC $=$ casein recovery from whey (\%); LACREC = lactose recovery from whey (\%); TSREC = total solids recovery from whey (\%); SNFREC = solids-not-fat recovery from whey $(\%)$.

use of protein, casein, and lactose, which consequently can increase the amount of cheese obtained in relation to batches produced with milk with higher somatic cell concentrations, which corroborates the findings of other authors (Tripaldi et al., 2003; Abd El-Gawad and Ahmed, 2011; Coelho et al., 2014).

Regarding the variable MY, it presented high weight for PC2 $(-0.2085)$ and a similar behavior to ASC, TCUTS, STRT, pH, and DENS (Figure 5), where the closest association was between it (MY) and ASC. The TCUTS also showed a significant high correlation with MY (Table 7). This fact corroborates the importance of dairy factories valuing good characteristics of the starter culture to be used in mozzarella processing. Added to this relationship, the yield, ASC, and other storage conditions (temperature, environmental humidity; not evaluated in the study) influence the characteristics of the final product. These factors are determinant for the activity of lactic acid bacteria, acidity, $\mathrm{pH}$ of the ingredients, and, consequently, its fermentative power and ability to provide the desired flavor and softness to the cheese (Moynihan et al., 2016). The variables PHCU and VMILK are located closer to the intercession of the axes (0.0), showing a more constant behavior and a lower association in relation to the others, and thus being less important for the variability of the data.

The 33 variables of the study can be summarized into 3 indexes, which explain $56.83 \%$ of the variability of the original data: index $1=-0.3038$ SNFREC - 0.2980CASREC $+\ldots+$ 0.0078TEMPRE; index $2=0.1000$ SNFREC + 0.1656CASREC $+\ldots+$ 0.1948TEMPRE; and index $3=0.0872$ SNFREC + 0.0196CASREC + . . 0.1042TEMPRE.

In spite of the 3 principal components reducing the size of the data, in this case the new variables (indexes) do not adequately represent the phenomenon, as they explain less than $60 \%$ of the variability of the 33 study variables. In general, these variables have little association, and the most important relationships occur between variables of the milk composition group and among those of the recovery of whey constituents group, which was also seen in the correlation analysis.

\section{CONCLUSIONS}

In the association analysis between MY and variables of milk composition, processing, and recovery of whey constituents, most of the correlations were positive. 
The main components of mozzarella showed that the yield has more relevant associations with $\mathrm{pH}$ and milk density, age of the starter culture, time elapsed between curd cuttings, and curd stretching time (Figure 6), indicating that these elements must be well controlled to achieve optimal efficiency in the manufacturing of this cheese. Exploratory analyses and Pearson correlation techniques have allowed us to understand the behavior of important variables for mozzarella cheese processing and the relationships established among them, albeit on a small scale. The presented results are suggestive for further studies on the yield obtained from buffalo milk mozzarella and may also support predictive studies, considering the variables that most significantly contributed to the data variability and that had significant associations with the object of study (cheese yield).

\section{ACKNOWLEDGMENTS}

D. C. Sales thanks the Higher Education Personnel Improvement Coordination (CAPES, Government of Brazil) for the research grant and all authors thank Francisco Veloso (Tapuio Agropecuaria, Taipu City, Rio Grande do Norte, Brazil) supporting the research.

\section{REFERENCES}

Abd El-Gawad, M. A. M., and N. S. Ahmed. 2011. Cheese yield as affected by some parameters review. Acta Sci. Pol. Technol. Aliment. 10:131-153.

Ahmed, N. S., M. A. M. Abd El-Gawad, M. M. El-Abd, and N. S. Abd-Rabou. 2011. Properties of buffalo mozzarella cheese as affected by type of coagulante. Acta Sci. Pol. Technol. Aliment. 10:339-357.

Altiero, V., F. Addeo, and P. Masi. 1984. Influenza dell'acidificazione della cagliata al momento della filatura sulla qualita e sulla struttura della Mozzarella di bufala. Latte 10:764-774.

Brazilian Association of Buffalo Breeders. 2014. Laticínios. Accessed Oct. 20, 2014. http://www.bufalo.com.br/laticinios.html.

Cecchinato, A., and G. Bittante. 2016. Genetic and environmental relationships of different measures of individual cheese yield and curd nutrients recovery with coagulation properties of bovine milk. J. Dairy Sci. 99:1975-1989. https://doi.org/10.3168/jds.2015-9629.

Cipolat-Gotet, C., G. Bittante, and A. Cecchinato. 2015. Phenotypic analysis of cheese yields and nutrient recoveries in the curd of buffalo milk, as measured with an individual model cheese-manufacturing process. J. Dairy Sci. 98:633-645. https://doi.org/10.3168/ jds.2014-8308.

Citro, A. 2010. Classificazione dei formaggi a pasta filata e tecnologia di produzione. Associazione Italiana Veterinaria Medicina Pubblica. Newsletter. 1:8-12.
Cochran, W. G., and D. F. Cox. 1978. Deseno Experimentales. Trillas, Mexico City, Mexico.

Coelho, K. O., A. J. Mesquita, P. F. Machado, M. E. Lage, P. M. Meyer, and A. P. Reis. 2014. Efeito da contagem de células somáticas sobre o rendimento e a composição físico-química do queijo Mozzarella. Arq. Bras. Med. Vet. Zootec. 66:1260-1268. https:// doi.org/10.1590/1678-7616.

Fagnani, R., P. E. Carraro, A. P. Battaglini, and J. P. A. Araújo. 2014. Alterações na densidade e crioscopia do leite pela adição de diferentes concentrações de Citrato e fortificante. Rev. Caatinga $27: 208-215$.

Furtado, M. M. 2005. Principais Problemas em Queijos: Causas e Prevenções. Fonte Comunicação e Editora, São Paulo, Brazil.

Furtado, M. M., and A. F. W. Pombo. 1979. Fabricação de queijo prato e Minas: Estudo do rendimento. Parte I. Determinação das cifras de transição. Revista do Instituto de Laticínios Cândido Tostes 34:1-48.

Gill, J. L. 1978. Design and analysis of experiments in the animal and medical science. Iowa State University Press, Ames.

Matysek, M. K., Z. Litwinczuk, M. Florek, and J. Barlowka. 2011. The effects of breed and other factors on the composition and freezing point of cow's milk in Poland. Int. J. Dairy Technol. 64:336-342. https://doi.org/10.1111/j.1471-0307.2011.00682.x http://dx.doi. org $/ 342$.

Moynihan, A. C., S. Govindasamy-Lucey, M. Molitor, J. J. Jaeggi, M. E. Johnson, P. L. H. McSweeney, and J. A. Lucey. 2016. Effect of standardizing the lactose content of cheesemilk on the properties of low-moisture, part-skim Mozzarella cheese. J. Dairy Sci. 99:7791-7802. https://doi.org/10.3168/jds.2016-11215.

Negri, L. M. 2005. Manual de Referencias técnicas para el logro de leche de calidad. 2rd ed. INTA. El ph y la acidez de la leche; p. 155-161. Accessed Oct. 12, 2014. http://www.aprocal.com.ar/wpcontent/uploads/pH-y-acidez-en-leche2.pdf.

Rangel, A. H. N., J. P. F. Oliveira, V. M. Araujo, K. C. Bezerra, H. R. Medeiros, D. M. Lima Júnior, and C. G. F. Araujo. 2011. Influence of the stage of lactation on the composition of milk of water buffalo. Acta Vet. Bras. 5:306-310. https://periodicos.ufersa.edu. br/index.php/acta/article/view/2315/5013.

Rossi, D., L. Abreu, and M. Furtado. 1998. Utilização do coalho bovino e coagulantes microbiano e genético na composição e rendimento do queijo Minas frescal. Revista do Instituto de Laticínios Candido Tostes. 53:8-14.

Sales, D. C., A. H. N. Rangel, S. A. Urbano, K. C. Borges, J. C. Andrade Neto, and B. M. E. Chagas. 2016. Cheese yield in Brazil: State of the art. Food Sci. Technol. (Campinas) 36:563-569. https://doi.org/10.1590/1678-457X.17116.

Shook, G. G. 1982. Approaches to summarizing somatic cell count which improve interpretability. Pages $150-166$ in Natl. Mastitis Counc. Annual Meeting. Natl. Mastitis Counc. Inc., Madison, WI.

Tonhati, H., G. M. F. Camargo, and R. R. Aspilcueta-Borquis. 2011. Programa de melhoramento genético de búfalos no Brasil: estado da arte. Pages 1-11 in Simpósio da Cadeia Produtiva da Bubalinocultura. International Symposium of Buffalo Production Chain, São Paulo, Brazil.

Tripaldi, C., S. Terramoccia, M. Bartocci, M. Angelucci, and V. Danese. 2003. The effects of the somatic cell count on yield, composition and coagulating properties of Mediterranean buffalo milk. Asian-australas. J. Anim. Sci. 16:738-742. https://doi. org/10.5713/ajas.2003.738. 